\title{
Los impuestos a la renta en el Perú
}

\author{
DISCURSO DE ORDEN, \\ PRONUNCIADO POR EL Sr. Dr. JUAN IINO CASTILLO, \\ CON MOTIVO DE LA INAUGURACION DEL AÑO ACADEMICO DE 1953
}

\author{
Eminentísimo Señor Gran Canciller de la Universidad. \\ Señor Fepresentonie del Excelentísimo señor Nuncio Apostólico, \\ Excelenísimo Señor Arzobispo Coadjutor, \\ Señor Rector. \\ Sres. Catedráticos, \\ Señoros, \\ Señores:
}

Antes de entrar en materia quiero agradecer a la Pontificia Universidad Católica del Perú el haberme confiado la honrosa responsabilidad ce pronuncicr el discurso de orden en esta actuación de apertura del año académico de 1953; y quiero, también, exponer los motivos que me han cieterminado a escoger como tema "Los impuestos a la renta en el Perú".

Lo he escogido por su importancia científica, por su evidente interés nacional, y por mi deseo de tratar de un problema que conozco directamente y a cuyo estidio puedo aportar algo propio.

No seró esta una disertación de carácter histórico. No voỳ c recordar cómo hun evolucionado los impuestos a la renta en el Perú, hasta concretarse en el sistema que hoy nos rige. Bástenos daber que tales impuestos siguieron lás diversas modalidades de nuestra economía.

Ne voy a ocupar, brevemente por cierio, de nuestro actual sistema de impuesics a la renta, comparándolo con los de los principales países de Europa y de América y con nuestra estructura nacional.

Señalaré sus méritos y deficiencias; $y$ me atreveré a sugerir los medios que se podría emplear para perfeccionar su estruciura $Y$ aplicación.

Entre los procedimientos que puede usar el Estodo a fin de procurarse los médios de pago indispensables para saitisfacer las necesidades públicas, para lograr el bien común, el impuesto es el principal. Supone la distribución de las cargas públicas entre todos los miembros de una comunidad políticamente organizada, según la capacidad de cada uno para contribuir $\alpha$ sostenerlas; $y$, apartándose del concepto neutral de la hacienda pública, hay la tendencia, cada día más acentuada, a usarlo como medio ae intervenir en la economía y aún de dirigirla.

El impuesto significa una trasferencia definitiva de poder de compra, a favor del Estado.

Jurídicamente, el impuesto es una prestación pecuniaria exigida por ei Estado a las personas privadas que poseen capacidad contributiva. Empleo los términos personas privadas, para destacar en la definición, que -tal 
capacidad no es exclusiva de las personas físicas, pudiéndosele atribuir a las personas jurídicas privadas, como las sociedades de capitales, pero nó a las personas públicas.

De ahí que sea común a todas las legislaciones positivas, el que la ley vincule el nacimiento de la obligación de pagar impuesto, a la realización de un hecho que revele la capacidad contributiva de la persona obligada. Tal capacidad puede manifestarse inmediatamente, por la propiedad de un patrimonio o la disponibilidad de una renta, o indirectamente, por una trasferencia de riqueza, o por el consumo. En el primer caso tenemos los impuestos directos, variables en función del patrimonio o de la renta del contribuyente; en el segundo, los impuestos indirectos, independientes dé uno y otra. Los primeros se aplican a la capacidad contributiva revelada por la propiedad o la adquisición de riqueza; los segundos a la revelada por su empleo. Son impuestos directos los impuestos a la fortuna y los impuestos a la renta; e indirectos; los impuestos a las transferencias y al consumo.

Se considera que entre todas las modernas formas de imposición ez el impuesto a la renta el que con aproximación mayor puede gravar la capacidad real del contribuyente, $y$ el que puede ser usado con mayor eficacia como instrumento de modificaciones económicas y sociales, esto sin desconocer la importancia financiera y también política que hoy reviste el impuesto indirecto sobre el gasto, impuesto cuyo rendimiento es de los más altos en muchos países y el más elevado en la Unión de las Repúblicas Saviéticas.

Es impuesto a la renta el que se exige a las personas privadas, en razón de su capacidad contributiva revelada por la renta de que pueden disponer. Pero la noción de renta, desde el punto de vista fiscal, no es uniforme. Así como en economía a la noción clásica de renta vínculada a la existencia de una fuente durable y a la periodicidad de su producción, se opone la que confunde la renta con el enriquecimiento experimentado por una persona de un período dado, así hay legislaciones positivas que gravan con impuesto a la renta solo la riqueza que fluye o puede fluir de una fuente, ya sea humana, material o mixta, es decir, la renta propiamente dicha, como lo hacen las de Gran Bretaña y Chile; otras legislaciones que gravan tanto la renta como las ganancias en capital, tales como las de Francia y de Argentina; $\mathrm{y}$, finalmente, otras que adoptan una posición intermedia, considerando las ganancias en capital dentro de un régimen particular, como la de Estados Unidos, o no considerando gravables sino determinadas ganancias en capital, como lo hace la legislación tributaria del Perú.

Todos los principales países, excepto México y Rusia, que sólo tienen impuestos cedulares, aplican un impuesto personal a la totalidad de la renta de las personas naturales, ya sea en forma del impuesto a la renta global de dichas personas, con tasas bósicas y sobre-tasas como en Estados Unidos, Canadá y Franciá, ya en forma de reconstrucción de la renta global, dentro del cuadro cedular, para gravarla con un impuesto de superposición. como en Inglaterra, Italia, Argentina, Brasil, Chile, Colombia, Venezuela Y el Perú. 
Este impuesto personal es, en realidad, el que pretende establecer la verdadera correlación entre la capacidad del contribuyente y el impuesto que le exige el Estado; y las tasas básicas y los impuestos cedulares que se aplican según la fuente de la renta, no son sino un primer escalón de tanteo, destinado a ser definitivo si la renta no excede de la cifra que la ley establece como mínima para aplicar el impuesto personal de tasas progresivas con el que se trata de alcanzar la igualdad de sacrificio entre los contribuyentes. El impuesto cedular sirve, también, para discriminar el peso de la carga impositiva, según la fuente que produce la renta, siendo de advertir que la regla hacendoria que señalaba el mayor peso para la renta del capital, el intermedio para la del capital y del trabajo combinado y el menor para el trabajo, ha perdido su valor absoluto, como resultado de las limitaciones legales al capital y de la protección legal a los trabajadores, emprendidas en mayor o menor escala en todos los países.

El sistema de impuestos $\alpha$ la renta que hoy rige en el Perú comprencie los impuestos a la renta propiamente dichos, el impuesto a las sobreutilidades de la industria y el comercio y un impuesto a las ganancias en capital derivadas de la transferencia de inmuebles, impropiamente llamado impuesto a la plus-valía.

Los impuestos a la renta propiamente dichos son diferenciados según las diversas rentas, a fin de graduar la intensidad de la imposición con arreglo a la durabilidad y seguridad de la fuente que las produce. A ellos se superpone un impuesto complementario, que es personal y progresivo si recae sobre el total de las rentas englobables, $y$ proporcional $y$ diferenciaco si grava rentas no englobables.

Tales impuestos entran en la clasificación, originariamente administrativa y hoy cidmitida por la ciencia de la hacienda pública, agrupa los impuestos de este tipo en impuestos cedulares e impuesto complementario.

Son impuestos cedulares: el impuesto sobre la renta del capital movible; el impuesto a los predios rústicos y urbanos; el impuesto a las utilidades industriales y comerciales; el impuesto a las utilidades de profesiones no comerciales $y$ el impuesto a los sueldos.

Además rige el impuesto de patente, supervivencia injustificable del antiguo régimen de tributación a la renta, que se aplica como licencia anual de ejercicio de la industria, el comercio y las actividades profesionales.

También existen tasas adicionales, con destino específico (pro desocupados), a los impuestos a la renta del capital movible, a los predios, a las utilidades industriales, comerciales y profesionales y a los sueldos.

El impuesto complementario es el que. la ley llama impuesto progresivo sobre la renta.

Nuestra legislación tributaria consagra la noción clásica de renta vinculada a una fuente durable que la produce o la puede producir periódicamente, excepto en el caso del impuesto a los beneficios obtenidos en la transferencia de inmuebles, que constituye un impuesto a las ganancias en capital.

En la aplicación de los impuestos a la renta la ley no establece discriminación entre contribuyentes nacionales $Y$ extranjeros. Constituye una excepción a esta regla general el tratamiento más favorable que la recien. 
te ley de petróleo dó a los concesionarios nacionales de la zona de la costa, al fijarles un porcentaje más alto de deducción por agotamiento que a los concesionarios extranjeros de dicha zona. tranjero.

La ley no autoriza ló deducción de los impuestos pagados en el ex-

El impuesto sobre la renta del capital movible se aplica a las perso nas que perciben intereses de operaciones de crédito. Es de tasas proporcionales, diferenciadas según el tipo de interés pactado. Se calcula sō̄re la renta bruta realmente percibida.

El impuesto a los predios debe ser pagado por los propietarios de inmuebles, y se aplica sobre la renta neta de arrendamiento, realmente pactada o supuesta por la administración tributaria. La tasa es proporcional $(7 \%)$.

El impuesto a las utilidades industriales $y$ comerciales se exige a las personas naturales o jurídicas que obtienen beneficios en el ejercicio de la industria o el comercio.

No existe en el Perú un impuesto distinto para las utilidades de las sociedades de capitales (anónimas, de responsabilidad limitada y en comandita por acciones), como en Francia, Estados Unidos, Canadó y Árgentina, ni un porcentaje distinto del impuesto $\alpha$ dichas sociedades, como en Chile.

La renta gravada es la utilidad neta, es cecir, la diferencix entre los ingresos brutos originados por la actividad propia de la empresa y las amortizaciones $\mathrm{y}$ cargas de la renta. Al determinar la renta imponible de las empresas mineras y petroleras se deduce, además, un porcentaje del valor bruto de la producción, por concepto de agotamiento de la fuente.

La noción legal de renta imponible es la clásica, como ya se ha dicho al tratar el punto en términos generales; pero se advierte en la administración tributaria la tendencia a desbordar dicha noción, gravando las ganancias en capital, como se ha hecho en el caso de revalorización de los inmuebles en los que con arreglo a ley deben invertir sus reservas técnicas las compañías de seguros.

Las tasas del impuesto a las utilidades industriales y comerciales son progresivas por escalones y van desde el $7 \%$, que se aplica a los primeros diez mil soles, hasta el $20 \%$ que grava toda utilidad que exceda de cien mil.

Existen tasas especiales de estímulo, para las empresas mineras que instalen nuevas plantas de beneficio o desarrollen su explotación o em. prendan explotaciones marginales, y para las empresas petroleras concesionarias conforme a la ley general de petróleo.

Las empresas agrícolas, ganaderas y pesqueras que exportan sus productos están sujetas a un régimen tributario especial. Se les cobra derechos aduaneros de exportación, acreditables como pago a cuenta de los impuestos a las utilidades y sobreutilidades de la empresa, pero cuyo exceso sobre el monto de estos impuestos no es reintegrable.

Tales derechos son generalmente calculados sobre la diferencia entre el precio de los productos $y$ el costo de producción fijado por el Go biemo o el precio base legal. 
Es de advertir que no existe impuesto a las utilidades no repartidas de las sociedades de capitales, lo que permite su autofinanciación; y que las utilidades de las empresas, sólo son gravadas dos veces: con el im. puesto cedular a las utilidades y con el complementario, en su forma progresiva o proporcional, según los casos.

En análoga condición, en cuanto al número de impuestoś que la grava, está la renta de las sociedades de capitales en Argentina, Brasil, Chile, México y Venezuela.

En cambio, en Francia es gravada tres veces: con el impuesto proporcional a los beneficios de dichas sociedades, con la tasa proporcional del impuesto a la renta global de las personas naturales $\mathrm{y}$ con las sobre. tasas progresivas del mismo impuesto; y en Estados Unidos, cuatro veces: con la tasa básica y la sobretasa del impuesto a las utilidades de la sociedad y con la tasa básica proporcional y las sobretasas progresivas del impuesto a la renta de las personas naturales.

En Inglaterra no hay esta múltiple imposición a las utilidades sociales, porque el "income tax" pagado por la sociedad es deducido del monto total del "income tax" y del "surtax" que corresponde a los contribuyentes a quienes se ha repartido la utilidad.

El impuesto a las utilidades profesionales grava la renta libre obte. nida del ejercicio de una profesión en el Perú. La renta libre se determina deduciendo de los ingresos brutos, además de las cargas de la renta, o sean, los gastos profesionales y las primas de seguro de vida pagadas por el contribuyente, la excepción en la base y las cargas de familia.

La tasa es de $6 \%$.

El impuesto a los sueldos es aplicable a las personas que obtienen renta derivada de servicios personales. Se calcula sobre la renta libre.

En la práctica, no se aplica a los salarios, aunque la ley no los exceptúa.

La tasa es de $5 \%$.

Los varones mayores de 35 años, solteros, viudos o divorciados sin hijos deben pagar este impuesto y el impuesto a las utilidades profesionales con un recargo de $25 \%$.

El impuesto complementario sobre la renta es un impuesto de superposición que se aplica para sobregravar con tasas progresivas las rentas englobables de las personas naturales, en razón de su magnitud, o para sobregravar, en la fuente, las rentas no englobables, tales como las percibidas de valores al portador y la obtenida del Perú por personas naturales no residentes o por personas jurídicas establecidas en el extranjero, rentas que no son gravadas con el impuesto complementario de tasas progresivas, por no ser posible a la administración tributaria conocer quienes ias perciben o exigir el impuesto directamente al beneficiario de ellas.

Las tasas que gravan las rentas no englobables son proporcionales $y$ diferenciadas según la clase de renta.

En algunos casos se aplica una tasa adicional de $1 \%$ pro-desocupados.

Nunstro sistema de impuestos a la renta propiamente dicho es análogo a los que rigen en los principales países latino-americanos, con ex- 
cepción de Colombia, que tiene un sistema sui-generis, $Y$ de México, que, como ya se ha dicho, aplica impuestos cedulares a las diversas rentas. También es análogo al nuestro, el sistema que rige en Italia.

En Estados Unidos la magnitud de las sociedades de capitales ha determinado el establecimiento de un impuesto diferente para las ut:lidades de las empresas organizadas bajo dicho régimen legal. Igual diferencia se encuentra en el Canadá y en Francia.

El impuesto a la renta de las personas naturales recae en Estados Unidos sobre el total de las rentas de cada contribuyente y comprende. una tasa bósica proporcional, y sobre tasas progresivas.

El impuesto francés a la renta global de las personas naturales comprende una tasa básica proporcional y sobretasas progresivas. La tasa básica y las sobretasas son aplicadas según criterios diferentes: el de lu territorialidad, para la primera, y los de la nacionalidad y el domicilio, parit las segundas.

El impuesto a las sobreutilidades industriales $y$ comerciales, que también integra el sistema de impuestos a la renta que rige en el Perú, es un inpuesto directo, de emergencia, que se aplica, con tasas progresivas por escalones, a las utilidades del comercio y de la industria (incluyendo la agricultura, la ganadería y la pesca y excluyendo la minería y el petróleo), en .cuanto exceden de lo que la ley establece como utilidad normal. La ley considera utilidad normal el $10 \%$ de los recursos de la empresa, habiendo podido optar las empresas establecidas antes del $1^{\circ}$ de julio de 1939, entre este $y$ el promedio de las ganancias que obtuvieron en los años 1938. 1939 y 1940.

Las tasas de este impuesto a las utilidades excesivas van del $10 \%$ aplicable a los primeros 50,000 soles, al $20 \%$ que grava toda cantidad que exceda de un millón.

Existe impuesto de emergencia a las sobreutilidades de la industria Y el comercio en Argentina, Chile, Estados Unidos y México, pero sobre bases más lógicas que las del que rige en el Perú.

En Colombia se aplica, como impuesto normal, un impuesto a las rentas excesivas que no provengan del trabajo.

El impuesto a los beneficios obtenidos de las transferencias de inmuebles no gravadas con impuestos a las utilidades industriales $y$ comerciales fué establecido como medio de evitar la evasión del impuesto a las utilidades de los comerciantes en inmuebles, èspecialmente en terrenos. Se aplica con tasas progresivas por escalones que van desde el $7 \%$ hasta el $15 \%$, sobre la diferencia entre el valor básico del inmueble fijado por la ley $y$ el precio pactado al realizarse la transferencia.

Es un impuesto a las ganancias en capital.

Aplicando al Perú el método de estudio seguido por Hubert Brochier en un reciente trabajo sobre estructuras nacionales y sistemas hacendarios, en el que demuestra que existe relación necesaria entre la estructura de un país y su sistema tributario, aparece la conformidad general de nuestro sistema de impuestos a la renta con nuestra estructura nacional.

A un país poco desarrollado como el nuestro, con muy elevado porcentaje de población dedicada a la agricultura y la ganadería $(62.44 \%$ 
de la población activa, en 1949), alta proporción de la renta de las mismas actividades (40\% de la renta tolal, también en 1949), débil industrialización. muy baja renta media (US\$ 77 por persona en el mismo año) y fuerte desigualdad en la repartición de la renta, corresponde naturalmente un sistema de impuestos diferenciados a la renta, como el que hoy nos rige y como los que existen, -también comò reflejo de su estructura nacional y no por obra del azar,- no sólo en los principales países de Ámérica latina (México, Argentina, Brasil, Chile y Venezuela) sino aún en países europeos de desarrollo económico intermedio, como España e Italia.

Esta relación necesaria entre estructura nacional y tipo de sistema tributario invita a los países poco déscrrollados a reflexionar ante la tentación de calcar sistemas fiscales propios de países industrializados.

Expuesto nuestro sistema de impuestos a la renta, comparado con los que rigen en otros países y confrontando con nuestra estructura nacional, examinemos las principales críticas que se le formulon.

Agruparemos dichas críticas según se refieran al sistema mismo i a su aplicación.

Al considerar las críticas al sistema, diferenciaremos las que recaẹn. sobre los impuestos a la renta propiamente dichos, de las que inciden sobre el impuesto a las utilidades o sobre el impuesto a las ganancias en capital obtenidas en la transferencia de inmuebles.

Se critica a nuestros impuestos a la renta por su complejidad; por establecer un régimen especial discriminatorio para las utilidades de las empresas agrícolas, ganaderas y pesqueras que exportan sus productos; por no permitir castigar el activo fijo de acuerdo con los precios de reposición: por intensificar la tributación a las rentas de la industria y el comercio; por usar la progresión en el impuesto a las utilidades industriales y comerciales; y por no haber conformado al actual poder adquisitivo de nuestra moneda las escalas progresivas del impuesto a las utilidades industriales y comerciales y del impuesto complementario.

Nuestros impuestos a la renta, lejos de ser complejos como se les supone, se caracterizan por su sencillez. Para convencerse de ello basta compararlos, no ya con los sistemas diferenciados que rigen en Ámérica Latina $\mathrm{Y}$ en algunos países de Europa, sino con los sistemas de impuesto global a la renta de las personas naturales e impuesto a la renta de las sociedades de capitales en vigor en Estados Unidos y en Francia, sistemas estos últimos que se singularizan por ser altamente complicados no obstante la simplicidad que un criterio superficial puede atribuirles for ser menor ei número de impuestos que los integran.

Por lo demás, cierto grado de complejidad es necesario para aseguIar la justa aplicación de los impuestos cada día más altos requeridos para el cumplimiento de los fines del Estado, y para evitar la evasión que lx creciente intensidad de la carga puede provocar.

Desde el punto de vista de la igualdad tributaria, es indefendible la discriminación existente en contra de las empresas agrícolas, ganaderas y pesqueras que exportan sus productos.

Sólo se explica por razones meramente fiscales. 
Es también justificada la crítica que se hace a la forma de calcular los castigos del activo fijo.

La intensidad de la tributación a las rentas de la industria y el camercio se explica por razones fiscales y por la importancia de dichas rentas dentro de la actual economía.

No creo que el empleo de la progresión en el impuesto a las utilidades comerciales $\dot{e}$ industriales constituya un contrasentido, porque no parece que tenga pòr objeto lograr la igualdad de sacrificio, como en el im. puesto complementario o en el de sucesión, sino desgravar a las rentas de menor cuantía.

En cambio, creo que es indispensable conformar las tarifas progresivas, al actual poder adquisitivo de nuestra moneda.

Aparte de lo justificado de algunas de las críticas que hemos examinado, nuestra legislación de impuestos a la renta es una obra seria que responde a nuestra estructura nacional y que refleja una política tributaria acertada, especialmente en cuanto contempla un tratamiento benigno para las rentas del trabajo y regímenes favorables al desarrollo de las industrias minera y petrolera cuya importancia es definitiva para el desenvolvimiento económico del país. Es, en general, sencilla y relativamente moderada. Hechos y comentarios recientes acreditan que sus condiciones son apreciados xor los inversionistas extranjeros.

Nuestro impuesto a las sobreutilidades de la industria y el comercio no reviste, en cambio, características apropiadas. Sus bases de cálculo son inactuales e inadecuadas y su tarifa en lugar de ser diferencial como las que rigen en Argentina, Chile y México, es progresiva, con lo que desnaturaliza la finalidad de dicho impuesio que es sobregravar los beneficios debidos no al esfuerzo a la inversión, sino a la coyuntura.

El impuesto a Iós beneficios derivados de la transferencia de inmuebles, aparte de romper la actitud general de nuestra legislación tributaria respectó a la noción de renta, es injusto y anti-económico. Se aplica no en razón de un mayor valor real, sino de una apariencia originada por la desvalorización de la moneda. Además, por su injusticia, incita y acostumbra al fraude fiscal.

Las principales críticas relacionadas con la aplicación de los impuestos a la renta se refieren a la complicación de los trámites, a lo tardío de las revisiones finales y a lo difundido de la evasión.

Son originadas por lo inadecuado de la organización de la administración tributaria, por la falta de métodos simples y uniformes, por la carencia de personal idóneo y por la ausencia de educación tributaria en el contribuyente.

Para perfeccionar la estructura de nuestro sistema de impuestos a la renta sería aconsejable realizar modificaciones parciales.

Assí, se podría someter a la agricultura, la ganadería y la pesca al régimen general, como se ha hecho con la minería y el petróleo, o, si razones fiscales inmediatas hicieran imposible esta solución, se podría adoptar el sistema de reajuste y reintegro que emplea Gran Bretañ $\alpha$ en la aplicación del "income tax" $\mathrm{y}$ del "surtax". 
También cabría formular nuevas tarifas progresivas con arreglo al poder adquisitivo actual de nuestra moneda, y permitir reajustes en la determinación de los castigos.

Sería, ademós, aconsejable modificar sustancialmente las bases de determinación de las sobreutilidades $y$ adoptar una tarifa diferencial en lugar de la progresiva que hoy rige; $\mathrm{y}$ suprimir el impuesto a los beneficios derivados de la transferencia de inmuebles.

En lo que se refiere a las medidas aconisejables para mejorar la aplicación de los impuestos a la renta, convendría reorganizar la administración, sobre la base de un criterio funcional; uniformar y simplificar los procedimientos, especialmente los relativos a la aplicación del impuesto a las utilidades de la industria y el comercio; seleccionar objetivamente al personal de la administración tributaria, darle ùna preparación adecuaḍa, tanto dentro del orden contable como del jurídico y remunerarlo debidamen. te; educar al contribuyente, mediante propaganda radial e información escrita; y preparar adecuadamente, en las Universidades, a los alumnos de las Facultades do Derecho y de Ciencias Económicas, que están llamados a ser los consultores obligados de los contribuyentes. 